БАЗАРКИНА Дарья Юрьевна - доктор политических наук, ведущий научный сотрудник отдела исследований европейской интеграции Института Европы РАН (125009, Россия, г. Москва, yл. Моховая, 11, cmp. 3; bazarkina-icspsc@yandex.ru)

\title{
ЭВОЛЮЦИЯ ПОДХОДА ЕВРОПЕЙСКОГО СОЮЗА К БОРЬБЕ С ДЕЗИНФОРМАЦИЕЙ
}

\begin{abstract}
Аннотация. В статье автор оценивает политическую и правовую базу, процесс эволюции и текущее состояние структур Европейского союза, ответственных за борьбу с дезинформацией. Выявлено, что механизм противодействия дезинформации в ЕС активно используется в политических целях. И ранее созданные инструменты, и решения 2020-2021 гг., вводящие общие для ЕС правила регулирования онлайн-контента, в ситуации дальнейшего ухудшения отношений ЕС и России могут быть использованы не только для защиты объективных прав граждан ЕС, но и для дискредитации нашей страны в рамках информационно-психологического противоборства.

Ключевые слова: дезинформация, гибридные угрозы, стратегическая коммуникация, Комиссия ЕС, Европейская внешнеполитическая служба, Россия
\end{abstract}

B официальных документах ЕС дезинформация определяется как «доказуемо ложная или вводящая в заблуждение информация, создаваемая, представляемая или распространяемая в целях получения материальной выгоды или намеренного обмана общественности» ${ }^{1}$ и оценивается как одно из средств реализации гибридных действий. Последние, согласно совместному сайту Европейского центра передового опыта по борьбе с гибридными угрозами и НАТО, направлены на подрыв или нанесение ущерба цели, влияние на принятие ею решений на местном, региональном, государственном или институциональном уровне ${ }^{2}$. На практике подход ЕС к борьбе с дезинформацией предусматривает применение широкого спектра средств - от информирования общественности до удаления онлайн-контента с помощью технологий искусственного интеллекта. Разные средства используются как непосредственно институтами ЕС, так и их партнерами.

С самого начала, помимо защиты объективных интересов (информационнопсихологической безопасности) граждан, система борьбы с дезинформацией создавалась как орудие информационно-психологического противоборства. Это видно и по официальным заявлениям институтов ЕС, и по целям и задачам профильных структур. Так, первой на данном направлении в 2015 г. была создана Восточная оперативная рабочая группа по стратегическим коммуникациям (East StratCom Task Force) в структуре Европейской внешнеполитической службы (ЕВС) «после призыва Европейского совета к реагированию на постоянные кампании дезинформации, проводимые Россией» 3 (призыв обусловлен

\footnotetext{
${ }^{1}$ ЕС активизирует борьбу ЕС с дезинформацией - вопросы и ответы. МЕМО/18/6648. European Commission. URL: https://ec.europa.eu/commission/presscorner/detail/ru/ MEMO_18_6648 (accessed 10.07.2021); Joint Communication to the European Parliament, the European Council, the Council, the European Economic and Social Committee and the Committee of the Regions. Action Plan against Disinformation. Brussels, 5.12.2018. JOIN(2018) 36 final.

${ }^{2}$ Hybrid threats as a concept. - Hybrid CoE - The European Centre of Excellence for Countering Hybrid Threats. URL: https://www.hybridcoe.fi/hybrid-threats-as-a-phenomenon/ (accessed 10.07.2021).

3 ЕС активизирует борьбу ЕС с дезинформацией -вопросы и ответы. МЕMO/18/6648. European Commission. URL: https://ec.europa.eu/commission/presscorner/detail/ru/ MEMO_18_6648 (accessed 10.07.2021).
} 
нарастанием украинского кризиса или даже более ранним «похолоданием» [Potemkina 2021: 258] в отношениях России и ЕС). Главная функция группы - разъяснение ценностей, интересов и политики ЕС в странах Восточного партнерства, для чего East StratCom Task Force, в частности, «повышает осведомленность о негативном влиянии дезинформации 〈... из прокремлевских источников 〈...> в информационном пространстве» ${ }^{1}$ Восточного партнерства и за его пределами ${ }^{2}$. Эти же цели, наряду с «укреплением» (strengthening) медиасреды путем поддержки независимых СМИ, перечислены в принятом в 2015 г. Плане действий в области стратегической коммуникации ${ }^{3}$ (базовое определение последней в Плане не дано). В документах, раскрывающих или затрагивающих проблему дезинформации, Россия также упоминается очень часто. Таким образом, не только борьба с дезинформацией, но и сама стратегическая коммуникация в ЕС изначально была подчинена задачам ограничения влияния экономического соперника и политического оппонента.

То, что борьба с дезинформацией де-факто составила основу стратегической коммуникации ЕС, видно по документам стратегического планирования. В 2016 г. была утверждена Общая рамочная программа ЕС по противодействию гибридным угрозам, где для борьбы с дезинформацией был провозглашен курс на усиление информационного обмена между государствами-членами, а также координацию действий ЕС по обеспечению стратегической коммуникации 4 . В то же время программа дает понять, что ЕС будет углублять сотрудничество с HATO. В 2018 г. в совместном сообщении ${ }^{5}$ Комиссия и Высокий представитель ЕС по иностранным делам и политике безопасности подчеркнули значимость стратегической коммуникации, в рамках которой наметили цель создания онлайн-платформы для борьбы с дезинформацией.

Рост влияния негосударственных акторов, в частности бизнес-компаний, располагающих большими массивами данных, средствами их анализа и использования в новостном менеджменте (в меньшей степени доступными институтам ЕС), заставил последние искать пути контроля над онлайн-пространством. Так, в сообщении, сделанном в апреле 2018 г. ${ }^{6}$, после скандального обвинения компании Cambridge Analytica во вмешательстве в электоральные процессы Комиссия ЕС представила подход к борьбе с дезинформацией в Интернете, обозначив задачи сделать действия онлайн-платформ более прозрачными и подотчетными ЕС. Среди прочих мер был предложен общеевропейский Кодекс практики по борьбе с дезинформацией (Code of Practice

1 Questions and Answers about the East StratCom Task Force. - European External Action Service - European Commission. URL: https://eeas.europa.eu/headquarters/headquartershomepage/2116/-questions-and-answers-about-the-east- (accessed 10.07.2021).

2 В декабре 2015 г. и июне 2017 г. соответственно ЕВС создала целевую группу по Западным Балканам и целевую группу по Югу для осуществления стратегической коммуникации в странах Ближнего Востока и Северной Африки и регионе Персидского залुива.

3 EU action plan on strategic communication. Ref. Ares(2015)2608242 - 22/06/2015. EU External Action Service. URL: https://eeas.europa.eu/sites/default/files/action_plan_on_ strategic_communication.docx_eeas_web.pdf (accessed 10.07.2021).

4 Security: EU strengthens response to hybrid threats. - European Commission - Press corner. URL: https://ec.europa.eu/commission/presscorner/detail/en/IP_16_1227 (accessed 10.07.2021).

5 A Europe that protects: EU works to build resilience and better counter hybrid threats. European Commission - Press corner. URL: https://ec.europa.eu/commission/presscorner/detail/ en/IP_18_4123 (accessed 10.07.2021).

6 Communication from the Commission to the European Parliament, the Council, the European Economic and Social Committee and the Committee of the Regions. Tackling online disinformation: a European Approach. COM/2018/236 final 
on Disinformation), по которому онлайн-платформы должны принимать меры вплоть до закрытия или демонетизации дезинформационных сайтов или профилей в социальных сетях. Также была провозглашена поддержка сети независимых фактчекеров (создана в 2019 г. в виде Европейской обсерватории цифровых медиа - European Digital Media Observatory ${ }^{1}$ ), а также инициативы по защите выборных процедур, развитию медиаграмотности. 12 сентября 2018 г. Комиссия опубликовала перечень мер по обеспечению свободных и честных выборов в $\mathrm{EC}^{2}$, среди которых - повышение прозрачности размещаемой в Интернете политической рекламы и возможность наложения санкций за незаконное использование персональных данных для намеренного влияния на результаты выборов.

Кодекс практики по борьбе с дезинформацией ${ }^{3}$ был подписан Facebook, Google, Twitter, Mozilla, а также рекламодателями и представителями рекламной индустрии в октябре 2018 г. Microsoft присоединилась к нему в мае 2019 г., a TikTok - в июне 2020 г. Основными мерами, принимаемыми онлайн-платформами, стало удаление аккаунтов и ограничение видимости сайтов, признанных дезинформационными. К сожалению, помимо противодействия дезинформации, распространяемой преступными акторами (к примеру, террористами), вполне вероятно применение Кодекса для ограничения свободы слова политических оппонентов ЕС, тем более что участие онлайн-индустрии в политическом противоборстве - явление не новое. Так, в 2017 г. Google объявила о намерении понижать в рейтинге репортажи государственных российских изданий $R T$ и Sputnik. Председатель холдинга Alphabet, владеющего Google, Эрик Шмидт заявил, что поисковому гиганту необходимо бороться с распространением дезинформации. Это вызвало протест со стороны $R T$ и Sputnik, которые располагают записью заявления Google в Конгрессе США, где говорится, что Google не обнаружила никакого манипулирования механизмами своей платформы со стороны $R T$ [Bazarkina, Pashentsev 2020]. ЕС заимствует опыт США, и в будущем не исключено более активное применение в ЕС алгоритмов онлайн-платформ (уже европейских) для установления повестки дня с помощью искусственного интеллекта.

Важным этапом институционализации борьбы с дезинформацией стало принятие в 2018 г. соответствующего Плана действий ${ }^{4}$, который обобщил предыдущие инициативы институтов ЕС. В Плане было закреплено определение дезинформации и перечень мер в отношении материалов, которые не нарушают законодательство ЕС. Борьба с дезинформацией опирается на четыре «колонны».

1. Расширение возможностей выявления, анализа и разоблачения дезинформации, в частности путем увеличения штата делегаций ЕС и Ячейки анализа гибридных угроз (EU Hybrid Fusion Cell). Мандат Восточной оперативной рабочей группы было решено сохранить, а двух других аналогичных групп (по Западным Балканам и Югу) - расширить.

${ }^{1}$ EDMO - United against disinformation. - European Digital Media Observatory. 2021. URL: https://edmo.eu/ (accessed 10.07.2021).

2 State of the Union 2018: European Commission proposes measures for securing free and fair European elections. - European Commission - Press corner. 2018. URL: https://ec.europa.eu/ commission/presscorner/detail/en/IP_18_5681 (accessed 10.07.2021).

${ }^{3}$ Code of Practice on Disinformation. - European Commission - Shaping Europe's digital future. 2021. Access: https://digital-strategy.ec.europa.eu/en/policies/code-practice-disinformation (accessed 10.07.2021).

4 Joint Communication to the European Parliament, the European Council, the Council, the European Economic and Social Committee and the Committee of the Regions. Action Plan against Disinformation. Brussels, 5.12.2018. JOIN(2018) 36 final. 
2. Единство реагирования учреждений и государств - членов ЕС. Решено, что Комиссия и Высокий представитель при участии государств-членов создадут Систему быстрого оповещения для борьбы с дезинформацией, сотрудничая с Европейским парламентом, НАТО и G7. Комиссия и Европарламент продолжат информирование граждан о ценностях и политике ЕС, активизируется стратегическая коммуникация.

3. Привлечение бизнес-структур: Комиссия берет на себя контроль реализации Кодекса практики по борьбе с дезинформацией.

4. Осведомление граждан о дезинформации: Комиссия и Высокий представитель в сотрудничестве с государствами-членами организуют кампании для общественности и тренинги для СМИ и лидеров мнений, поддерживают соответствующие СМИ и исследователей. Намечено создание групп независимых фактчекеров, запуск инструментов повышения медиаграмотности. Государствам-членам предписано обеспечить эффективное выполнение Пакета мер по проведению выборов.

Нужно отметить, что, несмотря на сохраняющуюся угрозу дезинформации, распространяемой негосударственными акторами, в частности террористическими организациями, актуальность принятия Плана официально объясняется тем, что «дезинформация со стороны Российской Федерации представляет наибольшую угрозу для ЕС»1.

Одновременно с принятием стратегических документов в ЕС развиваются и профильные структуры. В 2016 г. в составе ЕВС (еще точнее - подчиненного ей Ситуационного центра анализа разведданных, EU INTCEN) была создана уже упомянутая Ячейка анализа гибридных угроз, которая получает, обрабатывает и обменивается открытой и секретной информацией внутри ЕВС, а также с Комиссией и государствами-членами ${ }^{2}$. В задачи структуры входит разработка рекомендаций по борьбе с дезинформацией. Сотрудничество ЕС и НАТО получило развитие в создании в 2017 г. в Хельсинки совместного Центра передового опыта по противодействию гибридным угрозам (European Centre of Excellence for Countering Hybrid Threats). Материалы центра позволяют оценить не только основные направления борьбы ЕС с актуальными угрозами (к примеру, показательно внимание экспертов центра к проблеме злонамеренного использования искусственного интеллекта для подрыва информационно-психологической безопасности общества ${ }^{3}$ ), но и политический курс ЕС и НАТО. Как и в материалах Центра передового опыта в области стратегических коммуникаций НАTO в Риге, в публикациях центра в Хельсинки Россия названа государством, распространяющим дезинформацию ${ }^{4}$. Надо полагать, в данном контексте мы скорее всего увидим дальнейший рост давления на ЕС со стороны США в вопросе отношений с Россией.

\footnotetext{
1 Joint Communication to the European Parliament, the European Council, the Council, the European Economic and Social Committee and the Committee of the Regions. Action Plan against Disinformation. Brussels, 5.12.2018. JOIN(2018) 36 final. Part 2.

2 FAQ: Joint Framework on countering hybrid threats. - European Commission - Press corner. 2016. URL: https://ec.europa.eu/commission/presscorner/detail/it/MEMO_16_1250 (accessed 10.07.2021).

3 The future of cyberspace and hybrid threats. Hybrid CoE Trend Report 6. The European Centre of Excellence for Countering Hybrid Threats, 2021. URL: https://www.hybridcoe.fi/wp-content/ uploads/2021/04/20210407_Hybrid_CoE_Trend_Report_6_The_future_of_cyberspace_and_ hybrid_threats_WEB.pdf (accessed 17.11.2021).

4 Countering disinformation: News media and legal resilience. Hybrid CoE Paper 1. The European Centre of Excellence for Countering Hybrid Threats, 2019. URL: https://www. hybridcoe.fi/wp-content/uploads/2020/07/News-Media-and-Legal-Resilience_2019_HCPaperISSN.pdf (accessed 10.07.2021).
} 
18 марта 2019 г. в ЕС начала работу система оповещения о дезинформации цифровая платформа для обмена информацией о фейковых новостях и координации реакции на них. Участники системы - представители органов ЕС и государств-членов. Система имеет три основные функции: оперативное оповещение о кампаниях дезинформации; обмен аналитическими продуктами о тенденциях и способах распространения дезинформации; скоординированная реакция на кампании по распространению фейков ${ }^{1}$.

Процесс трансформации документов и структур показал, что до 2020 г. подход ЕС к борьбе с дезинформацией эволюционирует в контексте развития подхода к стратегической коммуникации - от пропаганды и контрпропаганды до развития способностей граждан распознавать дезинформационные сообщения, что выходит за рамки традиционных связей с общественностью. В то же время инструменты борьбы с дезинформацией активно используются для распространения обвинений в адрес России.

Крупный кризис, связанный, с одной стороны, с коронавирусной пандемией, а с другой - именно со стремительным ухудшением отношений ЕС и России, подтолкнул ЕС к серьезным мерам координации в исследуемой сфере. В конце 2020 г. проблемы борьбы с дезинформацией были затронуты в двух важных документах: Плане действий в области европейской демократии (European Democracy Action Plan) от 3 декабря ${ }^{2}$ и Законе о цифровых услугах (Digital Services Act) от 15 декабря ${ }^{3}$. В Плане действий в области европейской демократии борьба с дезинформацией выделена в качестве одного из трех главных направлений защиты демократических прав и свобод наряду с защитой честных выборов и демократического представительства и поддержкой независимых СМИ. Помимо ложной информации (misinformation) и дезинформации (disinformation), выделяются более целенаправленная информационная кампания влияния (information influence operation) и иностранное вмешательство в информационное пространство (foreign interference in the information space) ${ }^{4}$. Последнее раскрывается на примерах России и Китая, уже ставших хрестоматийными для документов ЕС.

В отличие от Плана действий по борьбе с дезинформацией 2018 г., где основное внимание уделялось разработке и донесению контрнарративов, в Плане 2020 г. Комиссия ЕС требует различных политических мер реагирования для каждого типа контента. К примеру, если ложная информация (misinformation), в которой нет намерения причинить вред обществу или извлечь экономическую выгоду, может быть устранена путем предоставления достоверной информации, то для борьбы с другими явлениями «необходимы более энергичные ответные меры». Таким образом, хотя в документе и прописано, что работа ЕС по борьбе с дезинформацией будет «основываться на европейских ценностях и

1 Шейко Ю. 2019. В ЕС запустили систему оповещения о дезинформации. - Deutsche Welle. 18 марта. Доступ: https://www.dw.com/ru/в-ес-запустили-систему-оповещения-одезинформации (проверено 10.07.2021).

2 Communication from the Commission to the European Parliament, the Council, the European Economic and Social Committee and the Committee of the Regions. On the European democracy action plan. COM/2020/790 final.

3 Proposal for a Regulation of the European Parliament and of the Council on a Single Market for Digital Services (Digital Services Act) and amending Directive 2000/31/EC. COM/2020/825 final.

${ }^{4}$ Communication from the Commission to the European Parliament, the Council, the European Economic and Social Committee and the Committee of the Regions. On the European democracy action plan. COM/2020/790 final. 
принципах и в полной мере обеспечивать свободу выражения мнений» ${ }^{1}$, План не исключает практику деранкинга или удаления онлайн-контента.

В общем виде направления борьбы с дезинформацией в Плане 2020 г. выглядят следующим образом.

1. Повышение потенциала ЕС и государств-членов по противодействию дезинформации. Включает разработку инструментария ЕС по противодействию иностранному вмешательству и операциям влияния, укрепление групп стратегической коммуникации и структур сотрудничества в борьбе с дезинформацией как в ЕС, так и на международном уровне. Планируется разработать общую методологию сбора доказательств иностранного вмешательства, а также увеличить поддержку национальных органов власти, СМИ и гражданского общества в третьих странах для выявления дезинформации и реагирования на нее и операции иностранного влияния.

2. Рост обязательств онлайн-платформ. Запланировано выпустить Руководящие принципы по устранению недостатков Кодекса практики по борьбе с дезинформацией (что и было сделано 26 мая 2021 г.) и создать постоянную основу для мониторинга его выполнения.

3. Вовлечение граждан. Поддержка инновационных проектов по борьбе с дезинформацией, а также инициатив по повышению медиаграмотности для «выявления дезинформации в ЕС и за его пределами» 2 .

Таким образом, в подходе ЕС обозначились две тенденции: рост значения негосударственных акторов и ужесточение мер противодействия контенту, признанному дезинформационным.

Закон о цифровых услугах включает лишь отдельные положения о дезинформации, которые, однако, свидетельствуют о большем, чем когда бы то ни было, стремлении Комиссии ЕС получить главные рычаги контроля контента: каждое государство-член должно будет назначить координатора цифровых услуг (Digital Services Coordinator), ответственного за контроль посредников в их поставках в своей стране и взаимодействие с национальными отраслевыми структурами. Государство-член определяет наказание за несоблюдение национального законодательства, соответствующего нормам ЕС, а координаторы могут налагать на нарушителей штрафы. В отношении самых крупных онлайн-платформ (обслуживающих более 45 млн потребителей в ЕС) Комиссия имеет прямые полномочия по надзору и может в случаях серьезных правонарушений налагать штрафы в размере до 6\% глобального оборота поставщика услуг ${ }^{3}$. Координаторы и Комиссия получают право требовать от онлайн-платформ немедленного устранения контента, признанного особенно вредоносным. Если платформы не принимают должных мер, предусмотрено судебное разбирательство. Закон о цифровых услугах вводит набор общих правил для всего ЕС - стандартизированные процедуры уведомления о незаконном контенте, равный доступ к механизмам подачи жалоб и возмещения ущерба, единый стандарт модерирования контента, стратегия действий в отношении крупнейших онлайн-платформ. Этот подход, безусловно, может помочь в борьбе с киберпреступностью (в частности, с фишингом) или террористической пропагандой, что необходимо для защиты прав и свобод

1 Ibid.

2 Communication from the Commission to the European Parliament, the Council, the European Economic and Social Committee and the Committee of the Regions. On the European democracy action plan. COM/2020/790 final.

3 Digital Services Act - Questions and Answers. - European Commission - Press corner. 2020. URL: https://ec.europa.eu/commission/presscorner/detail/en/QANDA_20_2348 (accessed 10.07.2021). 
граждан. Однако в контексте роста международной напряженности унифицированный подход к регулированию цифровой среды может быть использован и в информационных операциях против оппонента.

По Закону о цифровых услугах крупнейшие онлайн-платформы должны обеспечивать публичный доступ к хранилищам размещаемых рекламных объявлений для облегчения контроля и исследования рисков, связанных с незаконной рекламой, манипулированием и дезинформацией. Признано реальное негативное воздействие этих явлений «на здоровье населения, общественную безопасность, гражданский дискурс, участие в политической жизни и равенство» ${ }^{1}$, на что обращают особое внимание эксперты ${ }^{2}$. Таким образом, безопасность цифровых услуг тесно связывается на законодательном уровне с информационно-психологической безопасностью общества.

Закон предоставляет доступ к данным, которыми располагают онлайнплатформы, для координаторов цифровых услуг и Комиссии ЕС, а также для избранных исследователей (в т.ч. и по проблемам дезинформации). Комиссии ЕС и Европейскому совету по цифровым услугам (European Board for Digital Services, совещательный орган, состоящий из национальных координаторов) предписано поощрять разработку кодексов, направленных на выполнение закона. Особо в данном контексте выделены угрозы скоординированных операций с целью стремительного распространения контента (в т.ч. дезинформационного) ${ }^{3}$ с использованием ботов или поддельных учетных записей.

Наконец, Закон о цифровых услугах - шаг к созданию и институционализации системы оперативных кризисных коммуникаций, действующей в масштабах ЕС. «В случае чрезвычайных обстоятельств, влияющих на общественную безопасность или здоровье населения», Комиссия ЕС может инициировать ввод кризисных протоколов реагирования в онлайн-среде. Чрезвычайные обстоятельства в соответствии с законом могут означать «землетрясения, ураганы, пандемии и другие серьезные трансграничные угрозы здоровью населения, войны и террористические акты», вследствие чего «онлайн-платформы могут использоваться не по назначению для быстрого распространения незаконного контента или дезинформации» ${ }^{4}$. Ввод системы кризисных коммуникаций, в которую вовлечены институты ЕС, власти государств-членов и поставщики (прежде всего крупнейшие) онлайн-услуг, означает, с одной стороны, приближение механизмов коммуникации ЕС к практике и корпоративного коммуникационного менеджмента, в котором новость живет только 24 часа, и военной сферы, где почти все зависит от оперативности выполнения приказа. В настоящее время закон прошел несколько обсуждений в Совете ЕС и находится на рассмотрении в Европейском парламенте.

Можно заключить, что поле борьбы с дезинформацией в ЕС постоянно расширяется вместе с развитием стратегической коммуникации: если первые структуры, ответственные за нее, де-факто занимались пропагандой и контрпропагандой, то, к примеру, в Плане действий по борьбе с дезинформацией делается акцент на единстве реагирования. Это постепенно приближает общий подход ЕС к стратегической коммуникации к американскому, где последняя

\footnotetext{
1 Proposal for a Regulation of the European Parliament and of the Council on a Single Market for Digital Services (Digital Services Act) and amending Directive 2000/31/EC. COM/2020/825 final. Preamble, article 63.

2 Woods L. 2020. Overview of Digital Services Act. - EU Law Analysis. URL: https:// eulawanalysis.blogspot.com/2020/12/overview-of-digital-services-act.html (accessed 10.07.2021).

3 Proposal for a ... Digital Services Act. Preamble, article 68.

4 Ibid. Preamble, article 71.
} 
понимается как синхронизация «дел» (долгосрочная государственная политика), «слов» и «образов» (меры правительственной коммуникации) ${ }^{1}$.

В настоящее время в ЕС определены основные направления борьбы с дезинформацией, в основе создана ее нормативно-правовая база, аналитические и практические структуры. ЕС опирается как на собственные органы, так и на сотрудничество с частными компаниями и институтами гражданского общества. Помимо того, что такое сотрудничество позволяет получить дополнительные мощности, которыми институты ЕС пока не располагают (к примеру, массивы больших данных и более совершенные средства мониторинга), ответственность за удаление контента, оцененного как дезинформационный, но не нарушающего закон, лежит де-факто на негосударственных акторах. Военное измерение стратегической коммуникации (и в ее рамках - борьбы с дезинформацией) проявляется в активизации сотрудничества ЕС с НАТО, а в правовом регулировании - во включении войн в список чрезвычайных ситуаций в Законе о цифровых услугах.

Нельзя забывать, что стимулом для развития европейской системы борьбы с дезинформацией стал кризис, наступивший в отношениях ЕС и России с началом украинского конфликта. Термин «дезинформация» активно используется в институтах ЕС для обозначения материалов российских государственных СМИ. В контексте того, что присоединение Крымского полуострова к России оценивается в ЕС как аннексия, на восточном направлении внешней политики ЕС «борьба с дезинформацией» де-факто означает кампании в рамках информационно-психологического противоборства. Это отражается и в подходе, принятом в стратегических документах ЕС, где Россия, наряду с Китаем, систематически обозначается как государство, попирающее демократические гражданские права и свободы. В силу сказанного выше с возможным дальнейшим ухудшением отношений России и ЕС крайне важен систематический мониторинг материалов, опубликованных в рамках инициатив ЕС по борьбе с дезинформацией. Целесообразно развитие официальных планов и инструментов кризисной коммуникации, включая онлайн-инструменты, которые можно будет привести в действие с началом активных информационных кампаний, направленных на дестабилизацию отношений России и ЕС (в т.Ч. инициированных третьими сторонами).

\section{Список литературы}

Bazarkina D., Pashentsev E. 2020. Malicious Use of Artificial Intelligence. New Psychological Security Risks in BRICS Countries. - Russia in Global Affairs. Vol. 18. No. 4. P. 154-177.

Potemkina O. 2021. Chapter 13: Countering Transnational Security Threats. Principled Pragmatism in Practice: the EU's Policy towards Russia after Crimea (ed. by F. Bossuyt, P. van Elsuwege). Leiden: Brill. 390 p.

\footnotetext{
${ }^{1}$ White House, 2010. National Framework for Strategic Communication. White House Strategic Communications report to Congress, dated 16 March, released 17 March. Washington, DC: White House.
} 
BAZARKINA Darya Yur'evna, Dr.Sci. (Pol.Sci.), Leading Researcher of the Department of European Integration Research, Institute of Europe, Russian Academy of Sciences (bld. 3. 11 Mokhovaya St, Moscow, Russia, 125009; bazarkina-icspsc@yandex.ru)

\title{
EVOLUTION OF THE EUROPEAN UNION'S APPROACH TO COUNTERING DISINFORMATION
}

\begin{abstract}
The article assesses the political and legal framework, the process of evolution and the current state of the structures of the European Union responsible for countering disinformation. The EU's approach involves the use of a wide range of means - from informing the public to removing online content using artificial intelligence technologies. Different means are used both directly by the EU institutions and by their partners. The growing influence of non-state actors, in particular, business companies that have valuable big data amounts and analysis tools that are less accessible to EU institutions, forced the latter to look for ways to control the online space. The military dimension of strategic communication (and, within its framework, the struggle against disinformation) is manifested in the intensification of EU - NATO cooperation, and (in legal framework) in the inclusion of wars in the list of emergencies in the Digital Services Act.

The author reveals that the mechanism of countering disinformation in the EU is actively used for political purposes. Not only the struggle against disinformation, but also strategic communication itself in the EU was initially subordinated to the tasks of limiting the influence of economic rivals and political opponents. Both the previously created tools and the decisions of 20202021 that introduce common rules for regulating online content for the EU, in a situation of further deterioration of relations between the EU and Russia, can be used not only to protect the objective rights of European citizens, but also to discredit our country within the framework of psychological warfare.
\end{abstract}

Keywords: disinformation, hybrid threats, strategic communication, European Commission, European External Action Service, Russia 